\title{
REGRESSION EQUATION AND MULTIPLICATION FACTOR FOR THE RECONSTRUCTION OF STATURE BY FEMUR LENGTH
}

\author{
Raj Kumar Karki, ${ }^{1}$ Pankaj Kumar Singh, ${ }^{1}$ Abdul Sami Khan, ${ }^{1}$ Sudeep Regmi ${ }^{2}$
}

\begin{abstract}
\section{INTRODUCTION}

Stature is the important parameter along with age, sex and race while identifying bodies. Stature has direct relationship with the skeletal dimensions most importantly with lower limbs. This study attempts to derive regression equation (RE) and multiplication factor (MF) from femur length (FL) which could be used for stature reconstruction.
\end{abstract}

\section{MATERIAL AND METHODS}

The study was conducted amongst the 160 students and staff of Dhulikhel Hospital, Nepal for the period of six months from February 2020 to July 2020. The sample was composed of 95 males and 65 females between the age of 18 - 40 years. The femoral length and height was measured in standard position using standard measuring instruments. Statistical analysis was done using SPSS 25.

\section{RESULTS}

The mean height and femur length of overall sample was $162.33 \pm 7.62 \mathrm{~cm}$ and $40.14 \pm 2.132 \mathrm{~cm}$ respectively, male surpassing the female dimensions. There was a strong correlation between femur length and stature $(\mathrm{r}=0.723,0.869$ and 0.791 for males, females, and overall participants respectively). MF was derived as $4.084 \pm 0.139,3.99 \pm 0.11,4.047$ \pm 0.135 and $\mathrm{RE}$ was derived as $\mathrm{y}=75.51+2.13 * \mathrm{FL} \pm 4.06, \mathrm{y}=55.238+2.581 * \mathrm{FL} \pm 2.999, \mathrm{y}=48.791+2.829 * \mathrm{FL} \pm 4.672$ for males, females and overall participants. Both methods were checked for accuracy and could successfully interpret the height $(p>0.05)$.

\section{CONCLUSION}

The femoral length was found to be a reliable estimator of stature of an individual by using both RE and MF.

\section{KEYWORDS}

Femur length, Multiplication Factor, Regression equation, Stature.

1 Department of Forensic Medicine and Toxicology, Kathmandu University School of Medical Sciences, Dhulikhel, Nepal

2 Intern, Kathmandu University School of Medical Sciences, Dhulikhel, Nepal

DOI: http//doi.org/10.3126/jucms.v8i02.34265

\author{
For Correspondence \\ Dr. Raj Kumar Karki \\ Department of Forensic Medicine and Toxicology \\ Kathmandu University School of Medical Sciences \\ Dhulikhel, Nepal \\ Email: rkkarki17@yahoo.com
}




\section{INTRODUCTION}

Identification of a person means determination of its individuality, complete or partial. Complete identification absolutely fixes individuality whereas partial ascertains facts like race, gender, age, stature, etc. ${ }^{1,2}$ Accurate identification is mandatory for unclaimed bodies, portions of dead body or bones. ${ }^{3}$

Stature is height of the person in erect posture, or length of body from heel to vertex and can be used for establishing identification profile. ${ }^{3,4}$ No two populations have exact values for stature and bones. ${ }^{5}$ Long and weight bearing bones give most accurate measurement of stature. ${ }^{5,6}$ The mathematical method is based on MF or RE which is superior to anatomical methods that sums up bones. ${ }^{7-11}$ Intact femur has the highest correlation with stature and as such widely used in RE derivations. ${ }^{5,11,12}$ Karl Pearson for the first time derived RE using length of long bones like femur, tibia, humerus and radius. ${ }^{13}$ Later, Trotter and Gleser estimated stature in different races and concluded that racial differences exists, hence requiring different formulae. ${ }^{14}$ The present study was undertaken to create RE and MF for the determination of the relation of femur to stature in Nepalese population.

\section{MATERIAL AND METHODS}

This cross sectional study was conducted on healthy staff and students over a period of six months from February 2020 to July 2020 from different parts of Nepal, studying and working at Dhulikhel Hospital. Our sample comprised of 95 males and 65 females with age ranging from 18 to 40 years by random sampling method. The participants were screened by the investigators in the Department of Forensic Medicine. Any bony fracture, deformity or disease affecting the stature of the person like scoliosis, rickets, osteoporosis, history of dislocation of the vertebrae was excluded. Informed written consent was taken for taking measurements by non invasive technique. Prior to commencement of this study, the permission was taken from institutional ethical committee. Stature was measured by standiometer graduated in centimeters after removing footwear and headwear. The subjects were made to stand erect with head and neck straight in the middle and back of the standiometer. Middle of shoulders and buttocks touched standiometer, so that the Frankfurt plane remained horizontal. The feet was made slightly apart with the back of heels touching standiometer. ${ }^{15,16}$

Trochanteric length of the right femur was measured according to standard measurement technique. First the greater trochanter of femur was palpated and marked which is five inch below the tubercle of iliac crest. Then lateral condyle of femur was palpated and marked, keeping the right knee at 90 degree flexion. ${ }^{15}$ The trochanteric length of the femur was measured as the straight line between the highest points of the greater trochanter to the lowest point of the lateral condyle. A non-stretchable metallic tape graduated in centimeters was used to measure this length. ${ }^{12}$

The obtained data was entered and analyzed using statistical program for social sciences (SPSS) version 25.0. Descriptive statistics was done and presented as mean \pm SD. Data analysis was done to derive RE and MF. For assessing the correlation between the stature and the length of the femur, the Pearson's correlation coefficient was calculated and its significance was tested by students " $t$ " test. " $p$ " value of less than 0.05 was considered as significant. The relationship between stature and femur length was ascertained by simple linear regression to reconstruct stature. The final equation model was $y=(a+$ bx) \pm STE.

\section{RESULTS}

The analysis of our demographic data presented the age ranging from 18 to 40 years, $26.11 \pm 5.77$ years being the mean age. Mean height in our overall participants was $162.33 \pm 7.62$ $\mathrm{cm}$ and mean femur length being $40.14 \pm 2.132 \mathrm{~cm}$. However, there was no significant association between age and the actual stature. Other descriptive statistics of actual stature and femur length measurements of male, female and overall participants are outlined in Table 1 . The observed mean height was $166.31 \pm 5.845 \mathrm{~cm}$ and $156.51 \pm 6.011 \mathrm{~cm}$ and mean Femur length (FL) was $40.76 \pm 1.984 \mathrm{~cm}$ and $39.23 \pm 2.023 \mathrm{~cm}$ for male and females respectively. Mean of both were recorded significantly greater for male in comparison to female $(p<0.001$ by students t-test)

Table 1. Descriptive statistics of the participants

\begin{tabular}{|c|c|c|c|c|c|c|}
\hline Variables & Gender & Range & Mean \pm SD & $\begin{array}{l}\text { Mean diff } \\
\text { (cm) (male } \\
\text { vs. female) }\end{array}$ & $\mathrm{t}$ & $\mathrm{p}$-value \\
\hline \multirow{5}{*}{$\begin{array}{l}\text { Observed } \\
\text { stature } \\
(\mathrm{cm})\end{array}$} & Males $(\mathrm{n}=95)$ & $151.5-187.0$ & $166.31 \pm 5.845$ & \multirow{3}{*}{9.802} & \multirow{3}{*}{10.23} & \multirow{3}{*}{$<0.001$} \\
\hline & Females $(n=65)$ & $140.9-166.3$ & $156.51 \pm 6.0112$ & & & \\
\hline & Total participants & & & & & \\
\hline & $(\mathrm{n}=160)$ & $140.9-187.0$ & $162.328 \pm 7.62$ & \multirow{4}{*}{1.534} & \multirow{4}{*}{4.76} & \multirow{4}{*}{$<0.00$} \\
\hline & Males $(\mathrm{n}=95)$ & $34.3-45.1$ & $40.76 \pm 1.984$ & & & \\
\hline \multirow{2}{*}{$\begin{array}{l}\text { Femur } \\
\text { length } \\
\text { (cm) }\end{array}$} & Females $(\mathrm{n}=65)$ & $34.1-43.1$ & $39.23 \pm 2.023$ & & & \\
\hline & $\begin{array}{l}\text { Total participants } \\
\qquad(\mathrm{n}=160)\end{array}$ & $34.1-45.1$ & $40.14 \pm 2.13$ & & & \\
\hline
\end{tabular}

Femur length showed positive significant correlation with the observed stature in overall study population, males as well as females by Pearson's correlation test (Table 2). Our data presents stronger correlation coefficient $(r=0.87)$ in females entailing that femur of females have better correlation with stature than males $(r=0.723)$. The best fitting $R E$ for Nepalese population is ascertained for the stature reconstruction from femur length which is presented in Table $2 . \mathrm{R}^{2}$ value was $>0.500$ which denoted lower SEE and hence predictive accuracy was statistically significant for stature estimation in all groups. 
MF for Femur length was derived by dividing mean actual stature by femoral length. Significant male-female differences were observed from derived MF $(p<0.001)$, where male exhibited higher value. Mean MF was $4.084 \pm 0.139,3.99$ $\pm 0.11,4.047 \pm 0.135$ for male, female and overall participant respectively as shown in Table 2 .

Table 2. Regression equations (RE) and multiplication factors (MF) for prediction of stature

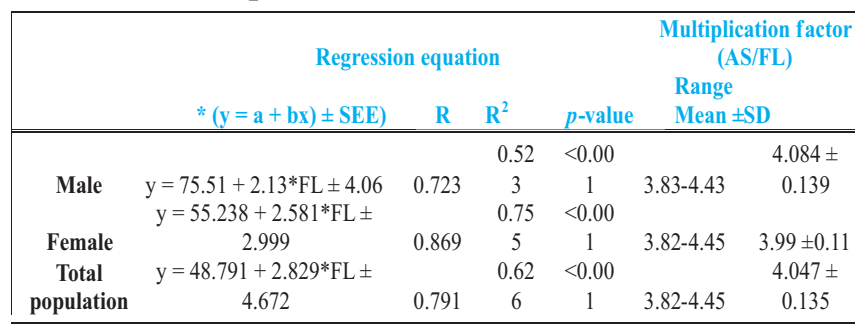

Here, *y (dependent variable score) = estimated stature from regression equation; $\mathrm{a}=\mathrm{y}$ intercept; $\mathrm{b}=$ regression coefficient; $\mathrm{x}=$ length of independent variable (Femur length/FL) and $\mathrm{SEE}=$ Standard error of estimate).

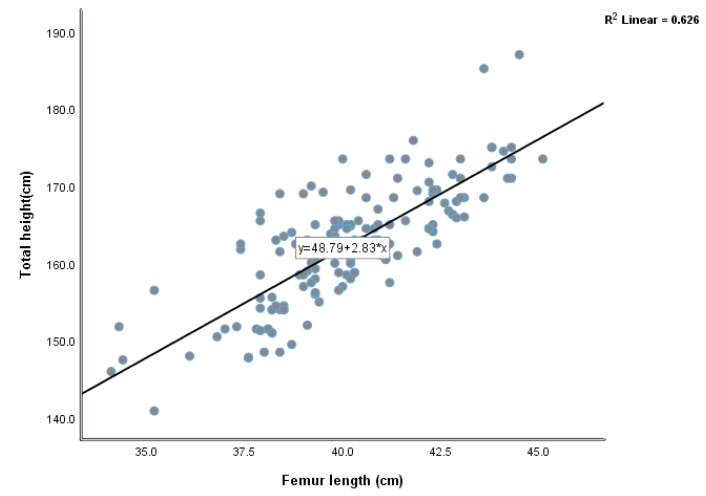

Figure 1. Scatter plot of overall study participant and derivation of regression equation

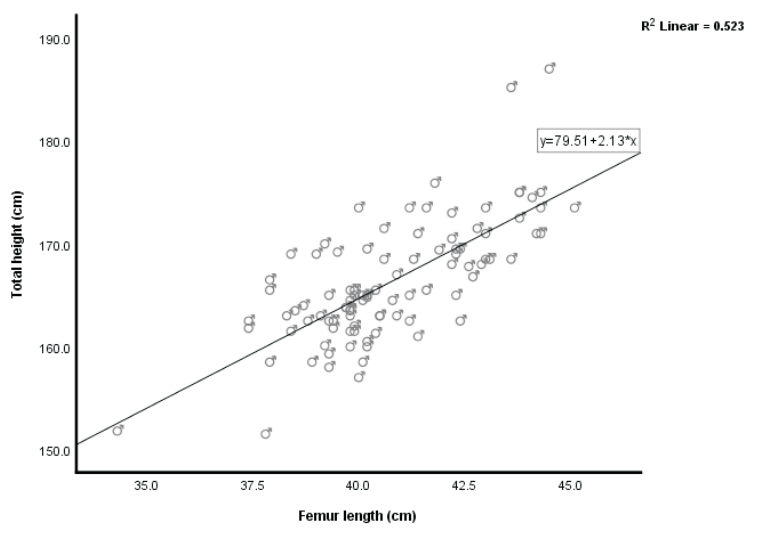

Figure 2. Scatter plot of male and derivation of regression equation

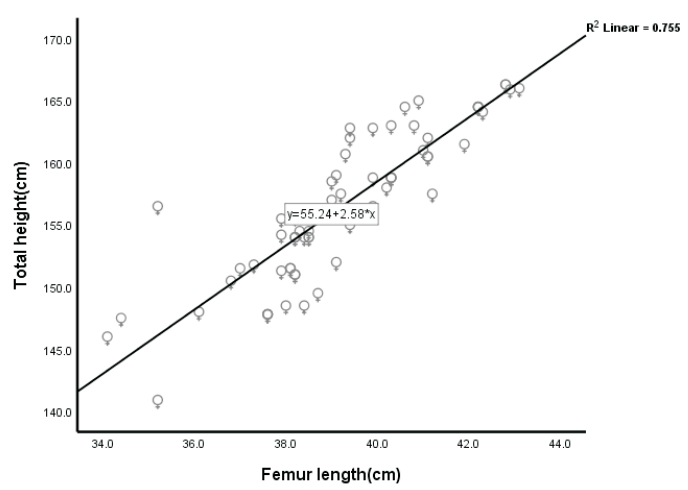

Figure 3. Scatter plot of female and derivation of regression equation

The above scatter plots show the positive correlation of femur length on $\mathrm{X}$-axis with stature on $\mathrm{Y}$-axis indicating that femur length were observed to be directly proportional to the stature on both gender and overall participants.

Table 3. Descriptive statistics of actual stature versus estimated stature from $\mathrm{RE}$ and $\mathrm{MF}$

\begin{tabular}{|c|c|c|c|c|}
\hline & & ${ }^{*} \mathrm{AS}(\mathrm{cm})$ & $\begin{array}{l}* * \mathrm{ES} \text { from } \\
* * * \mathrm{RE}(\mathrm{cm})\end{array}$ & $\begin{array}{l}\text { ES from } * * * * \mathrm{MF} \\
(\mathrm{cm})\end{array}$ \\
\hline \multirow{4}{*}{ Males (n=95) } & Range & $151.5-187.0$ & $152.53-175.53$ & $140.08-184.19$ \\
\hline & Mean & 166.309 & 166.2920 & 166.4770 \\
\hline & SE mean & 0.599 & 0.433 & 0.831 \\
\hline & SD & 5.844 & 4.224 & 8.103 \\
\hline \multirow[t]{4}{*}{ Females $(n=65)$} & Range & $140.9-166.3$ & $143.25-166.48$ & $136.16-172.10$ \\
\hline & Mean & 156.508 & 156.489 & 156.6423 \\
\hline & SE mean & 0.745 & 0.6480 & 1.00207 \\
\hline & SD & 6.011 & 5.2220 & 8.07896 \\
\hline \multirow[t]{4}{*}{ Total $(n=160)$} & Range & $140.9-187.0$ & $145.26-176.38$ & $138.02-182.54$ \\
\hline & Mean & 162.328 & 162.347 & 162.4667 \\
\hline & SE mean & 0.602 & 0.477 & 0.68200 \\
\hline & SD & 7.619 & 6.032 & 8.62900 \\
\hline
\end{tabular}

(*AS: Actual stature $* *$ ES: Estimated stature $* * * \mathrm{RE}$ : Regression equation $* * * * \mathrm{MF}$ : Multiplication factor)

Table 4. Mean difference amongst statures and error of estimate in stature estimation by RE and MF

\begin{tabular}{|c|c|c|c|c|c|c|c|c|c|c|}
\hline & \multicolumn{3}{|c|}{ AS-ESR } & \multicolumn{2}{|c|}{$\begin{array}{l}\text { Error of } \\
\text { estimate }\end{array}$} & \multicolumn{3}{|c|}{ AS-ESM } & \multicolumn{2}{|c|}{$\begin{array}{l}\text { Error of } \\
\text { estimate }\end{array}$} \\
\hline & Mean & $\begin{array}{c}\mathrm{t}- \\
\text { value }\end{array}$ & $\begin{array}{c}\mathrm{p}- \\
\text { value }\end{array}$ & $\mathrm{MU}$ & MO & Mean & $\begin{array}{c}\mathrm{t}- \\
\text { value }\end{array}$ & $\begin{array}{c}\mathrm{p}- \\
\text { value }\end{array}$ & $\mathrm{MU}$ & M0 \\
\hline Male & 0.017 & 0.04 & 0.968 & -8.48 & 12.87 & -0.167 & -0.291 & 0.772 & -10.69 & 12.17 \\
\hline Females & s 0.019 & 0.052 & 0.959 & -5.85 & 10.41 & -0.135 & -0.263 & 0.793 & -7.01 & 15.95 \\
\hline Total & -0.019 & -0.053 & 0.958 & -8.92 & 13.06 & -0.139 & -0.33 & 0.742 & -9.26 & 14.03 \\
\hline
\end{tabular}

(AS-Actual stature; ESR-Estimated stature from regression equation; ESM-Estimated stature from multiplication factor; MU-Maximum under estimation; MO-Maximum over estimation)

It is evident from Table 3 and 4 that mean stature derived from 
$\mathrm{RE}$ and MF was in close proximity to mean actual stature. No significant difference between them was seen by paired t test $(p<0.001)$. It suggests that RE and MF, both are useful for determination of stature from femoral length. However, there is broader range of stature estimation from MF and narrower from RE than actual stature. Standard deviation is lower for estimated stature from RE and greater for MF which implies stature estimated by MF is showing more dispersion from its mean value. On application of MF and RE, both maximum over and under estimation was done by MF except for stature estimation in males where overestimation was slightly greater in RE as per the error of estimates. Our statistical results revealed that the difference in mean between actual statures is greater with MF than RE for both sexes as well as for overall subjects. However, this difference was not significant $(p>0.05)$. Similarly, there was no significant difference between the two methods $(p>0.05)$. The difference between the mean was less than $1 \mathrm{~cm}$ by both methods so both can be a good estimator of stature.

\section{DISCUSSION}

The age range of adult population was selected from 18-40 years as stature at 18 years of age is accepted as adult stature for all practical purposes. ${ }^{17}$ The median increment for height ranges from $0.8 \mathrm{~cm}$ in males to $0.6 \mathrm{~cm}$ in females from $18-30$ years and decline is seen after the age of 40 years. ${ }^{18}$ Mean stature of our study population was found to be $162.33 \pm 7.62$ which was in close proximity to another study done in Nepalese population where mean height was $163.5 \pm 7.35$ in approximately same age group. ${ }^{2}$ However, our study was not consistent with other studies as stature tends to have geographical, nutritional and genetic variation ${ }^{2,10,12}$ underlining the need for population based study. Mean height of males and females in current study are $166.31 \pm 5.845 \mathrm{~cm}$ and $156.51 \pm 6.011 \mathrm{~cm}$ and mean femur length being 40.76 $\pm 1.984 \mathrm{~cm}$ and $39.23 \pm 2.023 \mathrm{~cm}$. In consistence with same and different innumerable studies done on height estimation, sexual dimorphism is seen in stature and long bones where male measurements surpass female..$^{12,13,18-21}$ These findings may be attributed to genetic reasons and puberty in females starting and ending approximately two years earlier than in males. ${ }^{18}$ This suggests that the formula for one sex cannot be applied to estimate stature for other sex.

Height of an individual is a sum of length of certain bones and appendages of the body ${ }^{13}$ hence wide variety of bones have been used to reconstruct stature like hand, foot, cranium, upper limb, clavicle etc. ${ }^{3,10,13,22-24}$ Nonetheless, long bones from lower limb has maximum contribution to stature and claim to provide near accurate results ${ }^{3,5,-12}$ but other bones might also be important in case of missing lower limb bones. ${ }^{3}$ Unlike to asymmetry in hand and foot length as studied by some authors ${ }^{19}$, there is existence of significant bilateral symmetry for long bones in humans. ${ }^{15,20-22}$ Thus, for maintaining uniformity, only right femur length was taken in our study.

In our analysis, as claimed by Pearson's correlation, ${ }^{13}$ femur length was directly proportional to stature indicating that taller people tend to possess longer limbs than their shorter counterparts. Analogous to our research, similar correlation was found in other studies working on femur. ${ }^{5,11,12,20,21}$ Likewise other bones radius, ulna, hand, foot, tibia all were also found to be positively correlated with stature..$^{3,5,10,15}$ We used simple linear regression analysis for derivation of regression equation for reconstruction of stature from femur length. However other studies have taken multiple bones where multiple regression equations are developed..$^{15}$ The computed RE and its correlation coefficient have been compared with other studies by Pearson $\mathrm{K}$, et $\mathrm{al}^{13}$ amongst French population, Trotter $\mathrm{M}$ and Gleser $\mathrm{GC}^{14}$ amongst Whites and Blacks, Kler GS and Kaur $\mathrm{H}^{25}$ amongst Punjabis, Bhavna, et al ${ }^{12}$ amongst Muslims, Soon LP, et $\mathrm{al}^{5}$ amongst Malaysians, Viquar, et $\mathrm{al}^{20}$ amongst North Indians and Shobha, et $\mathrm{al}^{11}$ amongst South Indians. As the factors like genetic diversity, cultural history, hormones, nutrition etc. influence the skeletal development, regression formulae are population and sex specific and can underestimate or overestimate the stature when employed in another population. ${ }^{5}$ Regression formulas do not predict the exact height but rather provides a range in which an individual's height is expected to fall. Present finding also observed strong correlation between stature and femur when compared with work of other authors. The regressions were cross validated in our study sample which showed no significant difference. We found less than $1 \mathrm{~cm}$ difference from the actual height which corroborated with other studies. $^{12,20}$ Many studies done in different bones for calculation of $\mathrm{RE}$ and $\mathrm{MF}^{2,10,15}$ have also found good correlation with stature. Similarly, Bhavna, et al found tibia to be the best estimator of stature compared to other bones of lower limb. ${ }^{12}$

Multiplication factor that was calculated in our study was compared with studies done by various authors from India and was in the range from 3.7 to 4.02 which was analogous to our finding. ${ }^{12,20,21,25}$ A study done in Chennai found the MF to be approximately four times of the actual stature which was homogenous with our result. ${ }^{23}$ We found stature estimation to be dependable from regression analysis than multiplication factor though there was no significant difference in their stature estimation which was consistent with other studies from different bones. ${ }^{6,19}$ Similarly in a study done to compare MF and RE analysis in foot and hand dimensions, ${ }^{6}$ they found $\mathrm{RE}$ being superior to MF for stature estimation as maximum under and overestimation was done by MF which was in accordance with our study. This connotes that RE derived for 
reconstruction of stature could be more reliable than MF. In contrary, some authors have advocated for multiplication factor. ${ }^{10}$ Nonetheless, MF is much handy and could be used for preliminary estimation of stature.

This is population specific preliminary study and the regression equation and multiplication factor is specific for Nepalese population only. So, we require further research involving wide range of population. Further, we also opine the need of ethnic group and population specific RE and MF. However, these equations are population specific and cannot be applied to other population as stature reconstruction using norms of other population is bound to give incorrect results. It would be good to extend the study to include other parts of Nepal including other bones as well.

\section{CONCLUSION}

In the present study, three univariate linear regression equations and multiplication factors to estimate stature from Femur Length for Nepalese population were derived. A positive and strong association between stature and femur length dimensions was observed which could reliably reconstruct stature. Hence, the current finding further strengthened the prior claims of long bones being good estimator of stature which would help to identify human remains.

\section{ACKNOWLEDGEMENT}

The authors would like to thank all the staff and students of Kathmandu University School of Medical Sciences who participated in the study.

\section{REFERENCES}

1. Vij K. Text Book of Forensic Medicine and Toxicology. $4^{\text {th }}$ ed. New Delhi: B I Churchill Livingstone Pvt Ltd. 2008;4:46-89.

2. Yadav SK, Mandal BK, Karn A. Determination of stature from ulnar length in Nepalese population. Eur J Forensic Sci. 2015 Jan-Mar;2(1):5-8.

3. Anwar S, Mubarak WA, Ouies S, Elsheikh M. Lower limb and foot dimensions and their correlations with body height in adult population of Aswan Governorate. Stem Cell. 2019;10(2).

4. Krogman WM, Iscan MY. Calculation of stature. In: The Human Skeleton. Forensic Medicine. $2^{\text {nd }}$ ed. USA: Charles C Thomas Publishers. 1986;305-338.

5. Soon LP, Hasmi AH, See KL, Mohamad Noor MH, Feng SS. Stature estimation by using postmortem computed tomography scan images of long limbs. Ann Forensic Res Anal. 2017;4(2):1041.
6. Krishan K, Kanchan T, Sharma A. Multiplication factor versus regression analysis in stature estimation from hand and foot dimensions. Journal of Forensic and Legal Medicine. 2012;19:211e-214.

7. Parikh. Personal Identification. In: Parikh's Text Book of Medical Jurisprudence, Forensic Medicine and Toxicology. $6^{\text {th }}$ ed. New Delhi: CBS Publishers, 2006;2.1-2.92

8. Hauser R, et al. The estimation of stature on the basis of measurements of the femur. Forensic Sci Intl. 2005;147(2):185190.

9. Singh, et al. Regression equation for estimation of femur length in Central Indians from inter-trochanteric crest. J Indian Acad Forensic Med. July-September 2013;35(3).

10. Venkatachalam KSM, Felix JW. Prediction of stature with regression equation and multiplication factor using foot length in adults: A comparative study. International Journal of Contemporary Medical Research 2019;6(1):A1-A4.

11. Shobha, Pravinkumar N. Kamaradgi, Pragnya Rao, Vijayakumar B Jatti. Estimation of stature from radiological length of femur among South-Indian adult population. International Journal of Contemporary Medical Research. 2019;6(7):G1-G4

12. Bhavna, Surinder N. Estimation of Stature on the basis of measurement of the lower limbs. In: Anthropology Special. 2007;3:219-22.

13. Pearson K. cited by Krogman WM. Mathematical contribution to the theory of evolution V. On the reconstruction of stature of pre-historic races. Philosophical Transection of Royal Society London. 1899;192:168-224.

14. Trotter M, Gleser GC. Estimation of stature from long bones of American Whites and Negroes. AJPA. 1952;10:463-514.

15. Ismail, et al. Stature estimation in Malaysian population from radiographic measurements of upper limbs. Egy J Forensic Sci. 2018;8:22.

16. Chaurasia BD. Surface anatomy. BD Chaurasia's Human Anatomy $4^{\text {th }}$ ed. Vol II. New Delhi: CBS Publishers \& Distributors, 2004;163.

17. Chandler PJ, Block RD. Age changes in adult stature: Trend estimation for mixed longitudinal data. Ann Hum Biol. 1991;18:433-440.

18. Ozun et al. Estimation of stature from upper extremity anthropometric measurements. Journal of Clinical and Diagnostic Research. 2019 Jan;13(1):AC09-AC15.

19. Varu et al. Determination of stature from hand dimensions. The Journal of Medical Research. 2015;1(3):104-107.

20. Viquar and Khanna. Estimation of stature from femur length in North Indian male population. Indian Journal of Forensic and Community Medicine. Jul -September, 2018;5(3):153-156. 
21. Kumar P, Shahnawaz K, Varma G. Study of estimation of stature by the length of femur. Journal of Evolution of Medical and Dental Sciences. 2014;3(12):3166-72.

22. Shankar GS, Shankar VV, Shetty S, Radhika K. Correlation of human height with foot length in Indian individuals. Int J Anat Res. 2018;6(1.2):4943-4946.

23. Pushparathna SB. Determination of height using femur length in adult population. Drug Invention Today. 2019;12(4):834-35.

24. Nandi, et al. Stature reconstruction from percutaneous anthropometry of long bones of upper extremity of Nigerians in the University of Lagos. Arab Journal of Forensic Sciences \& Forensic Medicine. 2018;1(7):869-80.

25. Kler GS and Kaur H. Estimation of stature from the length of femur in Punjabis. J Forensic Med and Toxicology. 1994;X:1216 